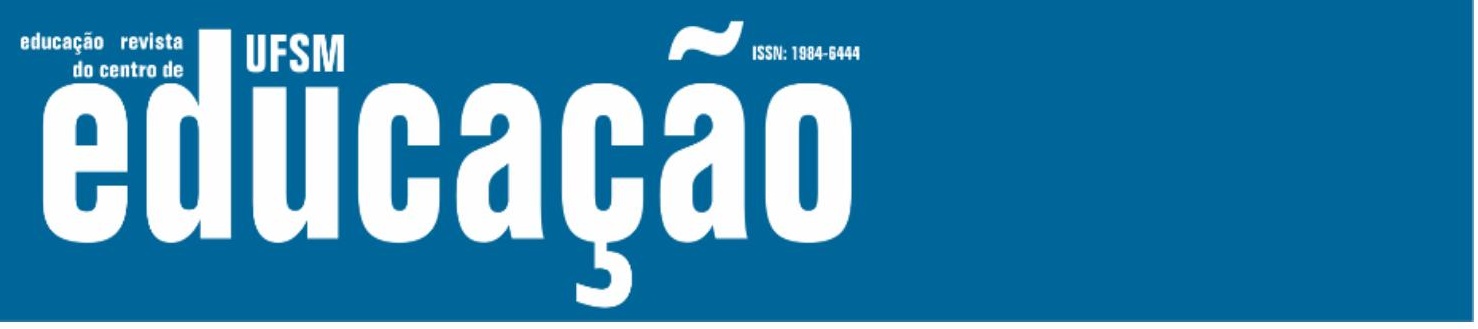

ISSN: 1984-6444 | http://dx.doi.org/10.5902/1984644455163

\title{
Vozes de Professores: Política Municipal de Alfabetização de Manaus em Debate ${ }^{1}$
}

\author{
Teachers' Voices: Manaus Municipal Literacy Education Policy Under \\ Discussion.
}

Raiolanda Magalhães Pereira de Camargo

Doutoranda do Programa de Pós- Graduação em Educação na Amazônia- PGEDA-EDUCANORTE, Manaus, Amazonas, Brasil .

Professora da Faculdade de Educação da Universidade Federal do Amazonas, Manaus, Amazonas, Brasil

landacamargo@hotmail.com - http://orcid.org/0000-0002-6839-1920

Selma Suely Baçal Oliveira

Professora Doutora da Faculdade de Educação da Universidade Federal do Amazonas, Manaus, Amazonas, Brasil.

selmabacal@ufam.edu.br - http://orcid.org/0000-0001-6765-4568

Recebido em 10 de setembro de 2020

Aprovado em 26 de março de 2021

Publicado em 28 de maio de 2021

\section{RESUMO}

Este artigo apresenta os resultados parciais das ações do movimento de resistência denominado Política Municipal de Alfabetização de Manaus em debate, organizado por professores da Educação Infantil, dos Anos Iniciais do Ensino Fundamental, pedagogos da Secretaria Municipal de Educação de Manaus (SEMED), Sindicato dos Trabalhadores em Educação do Estado do Amazonas (SINTEAM), professores e pesquisadores da Faculdade de Educação da Universidade Federal do Amazonas diante da Minuta de Lei da Política Municipal de Alfabetização, apresentada pela SEMED/Manaus. O estudo partiu da análise proposta na Minuta, considerando seu aspecto teórico-metodológico, bem como do contexto de sua apresentação (em uma pandemia da COVID-19), tempo destinado para análise e ausência de representatividade de profissionais da educação nas discussões. A proposta da SEMED se alinha às proposituras do Decreto Federal n 9.765, de 11 de abril de 2019, que institui a Política Nacional de Alfabetização, que neste estudo também será analisada, à luz das considerações críticas, que apontam seus limites e problemas conceituais, epistemológicos, políticos, pedagógicos e metodológicos levantados pelos principais pesquisadores brasileiros no campo da alfabetização e discutidos no Dossiê "Política Nacional de Alfabetização em foco: olhares de professores e pesquisadores", organizado pela Associação Brasileira de Alfabetização. Os resultados evidenciam a necessidade do fortalecimento de uma ação coletiva com 


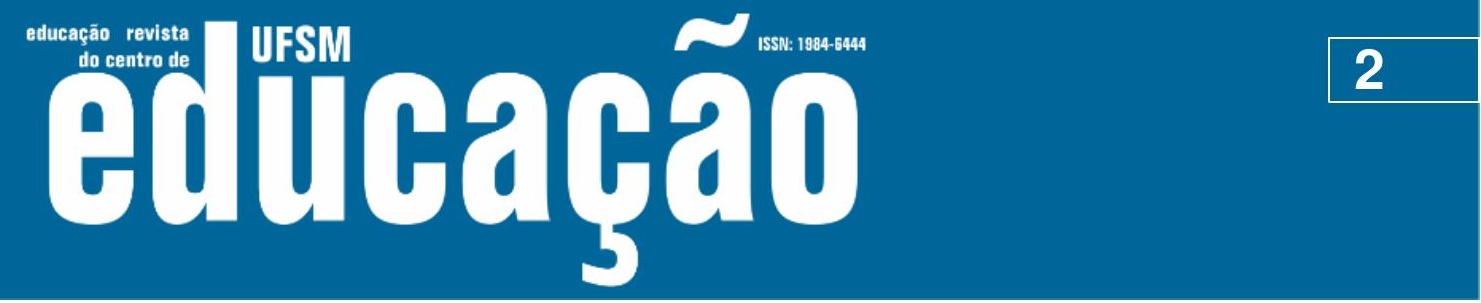

ISSN: 1984-6444 | http://dx.doi.org/10.5902/1984644455163

participação de representantes das universidades, associações científicas, professores e outros representantes da sociedade civil brasileira para o surgimento de políticas educacionais que considerem as experiências em andamento, as vozes dos professores e o desejo da escuta de suas reais necessidades, emancipação e valorização docente.

Palavras-chave: Vozes de professores; Política Municipal de Alfabetização; Política Nacional de Alfabetização.

\section{ABSTRACT}

This article introduces the partial results of actions of a resistance movement called "Manaus Municipal Literacy Education Policy under discussion". It has been organized by Childhood Education teachers, Elementary School teachers, Educators from Manaus Municipal Education Department, Education Workers Union of Amazonas State, professors and researches from Education College of Federal University of Amazonas before the Draft Law of Municipal Literacy Education Policy presented by SEMED/Manaus. The study stemmed from the analysis proposed in the Draft Law, considering its theoretical-methodological aspect, as well as the context of its presentation (during COVID -19 pandemic). It was a time aimed for analysis and lack of representativeness of Education professionals in discussions. SEMED's proposal aligns to the propositions of the Federal Decree $n^{\circ}$ 9.765, from April 11th, 2019, which establishes the National Literacy Education Policy. The same will be analyzed in the light of critical considerations that indicate its limitations and conceptual, epistemological, political, pedagogical and methodological problems observed by the main Brazilian researchers in the Literacy Education field. They will be discussed in the Dossier "National Literacy Education Policy in focus: researchers and professors' perspectives", organized by Brazilian Literacy Education Association. The results highlight the need to reinforce a collective action with participation of representatives from universities, scientific associations, professors and other Brazilian civil society representatives for the emergence of educational policies that consider ongoing experiences, the teachers' voices as well as the desire to listen their real needs, emancipation and professional valorization.

Keywords: Teachers' voices; Municipal Literacy Education Policy; National Literacy Education Policy. 


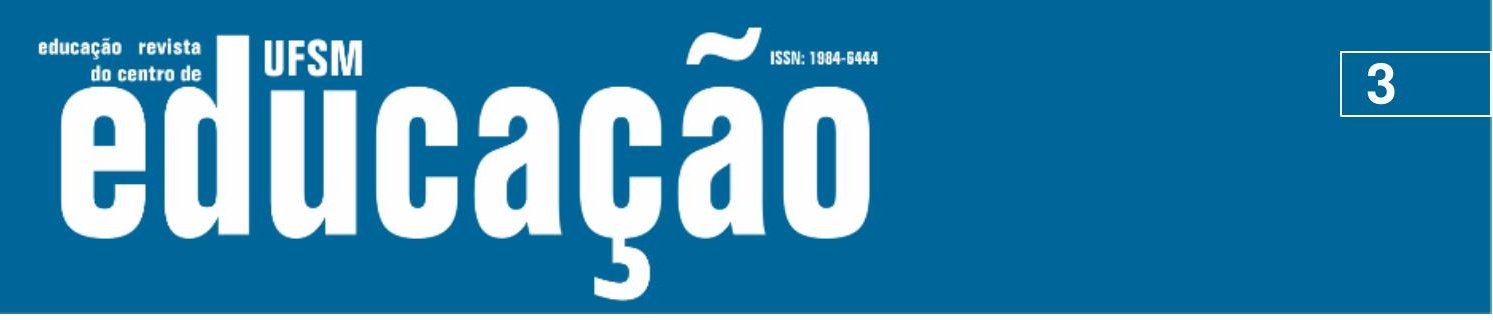

ISSN: 1984-6444 | http://dx.doi.org/10.5902/1984644455163

\section{Introdução}

O Movimento Política Municipal de Alfabetização em debate é uma ação coletiva de resistência organizada por professores da Educação Infantil, dos Anos Iniciais do Ensino Fundamental, pedagogos da Secretaria Municipal de Educação de Manaus (SEMED), Sindicato dos Trabalhadores em Educação do Estado do Amazonas (SINTEAM) e professores e pesquisadores da Faculdade de Educação da Universidade Federal do Amazonas diante da apresentação da Minuta de Lei da política municipal de alfabetização, alinhada com a Política Nacional de Alfabetização (PNA), antidemocrática e pseudocientífica do governo Bolsonaro.

A PNA representa um golpe na democracia e na ciência produzida no Brasil nos últimos quarenta anos sobre alfabetização, provocando uma grave ruptura com as políticas públicas já implementadas, por adotar um único caminho metodológico e teórico, ancorado na ciência cognitiva da leitura, destoando dos instrumentos normativos vigentes, que englobam um conjunto de leis, decretos, Plano Nacional de Educação, Diretrizes Curriculares específicas das etapas e modalidades da Educação básica e a Base Nacional Comum Curricular, documento orientador e obrigatório das propostas curriculares das redes e sistemas de ensino municipal.

Desse modo, é na esteira de uma política de estado mercantilista criada para atender uma agenda de privatização, que a Minuta de Lei da PMA é construída, com o apoio da atual gestão da Secretaria Municipal de Educação de Manaus (SEMED). Salientamos que a SEMED, há oito anos, vem se rendendo à lógica do mercado privatista, efetivada pelo Projeto de Expansão e Melhoria Educacional da Rede Pública Municipal de Manaus (PROEMEM), executado pela SEMED e financiado com recursos do Banco de Desenvolvimento (BID), juntamente com os recursos previstos no orçamento da própria secretaria, expandindo, assim, a presença direta do setor privado. Essa lógica do mercado presente na educação pública municipal de Manaus vem sendo traduzida em um extenso volume de contratos, convênios e acertos entre a SEMED e os setores privados, permitindo a apropriação privada do bem público (ARANHA; OLIVEIRA, 2019). 


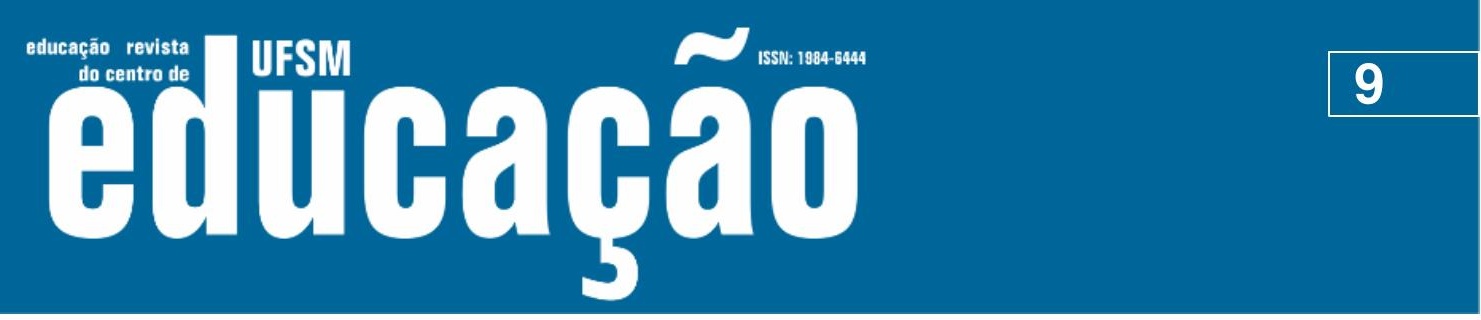

ISSN: 1984-6444 | http://dx.doi.org/10.5902/1984644455163

Além disso, compreendemos que o ensino e aprendizagem da leitura e da escrita são condicionados por fatores sociais, culturais, econômicos e políticos que configuram a alfabetização como um processo de grande complexidade, com pressupostos teóricos e implicações pedagógicas, traduzidas em saberes e fazeres diversos. A natureza do conceito de alfabetização deve ser caracterizada não como uma habilidade, mas um conjunto de habilidades que exigiria uma integração dos estudos de diversas facetas. Desse modo, a questão metodológica presente no desenvolvimento de práticas alfabetizadoras, demanda de uma conjugação das contribuições de diversos campos do conhecimento como a linguística, a psicolinguística, a sociolinguística, a psicologia, além dos paradigmas epistemológicos que apresentam saberes e fazeres para a ação alfabetizadora. (SOARES, 2017).

$\mathrm{Na}$ carta aberta, publicada no IV Congresso Brasileiro de Alfabetização, promovida pela Associação Brasileira de Alfabetização (ABAlf), em agosto de 2019, na cidade de Belo Horizonte, assinada por pesquisadores, professores e estudantes de diversos estados brasileiros, é incentivado o pluralismo teórico e metodológico para as práticas alfabetizadoras na luta para a universalização da alfabetização.

Maciel (2019) chama atenção para a composição dos vinte especialistas colaboradores que redigiram o documento: são 13 especialistas, cuja formação e atuação são na área de psicologia; 2 na área de linguística e 5 na área de educação e apenas 1 com formação em pedagogia, sendo 8 estrangeiros e 12 brasileiros com vínculos em universidades públicas e privadas, que atuam nas áreas das ciências cognitivas, psicologia cognitiva e neurociência. A autora questiona sobre qual o papel da educação e dos alfabetizadores em uma política nacional majoritariamente construída com o viés da psicologia.

Ao invés de políticas públicas pautadas em discursos salvacionistas, está na hora de pensar as formações dos professores como um permanente desafio, que implica essencialmente em considerar os alfabetizadores e alfabetizandos como sujeitos produtores de história e de cultura, e cujos saberes e fazeres devem ser alicerce para a criação de novos programas de formação, capazes de garantir o direito humano e social de aprender a ler e a escrever para todas as crianças brasileiras. 
É justamente para atender essa agenda de privatização, com o interesse de satisfazer os interesses do mercado, em especial o editorial, que a PNA se abre às pressões lobistas para a disseminação de ideologias exclusivistas e para a venda de materiais didáticos, alimentando as editoras, institutos e fundações, certamente que com o dinheiro público.

Outro aspecto da PNA que demanda ser evidenciado, diz respeito à inserção das crianças da Educação Infantil em uma política nacional de alfabetização, mostrando uma intencionalidade de exigência de objetivos e conteúdos específicos dos anos iniciais do Ensino Fundamental, que fere os princípios e concepções presentes em outros instrumentos normativos em vigência, como a LDB 9.394/96, as Diretrizes Curriculares Nacionais para a Educação Infantil (BRASIL, 2009) e a BNCC, além de contrariar as pesquisas sobre a primeira infância e Educação Infantil, que defendem o respeito às características do pensamento infantil, preconizando que o contato com a cultura escrita deve se dar por meio das brincadeiras e interações, em conjunto com outras linguagens, silenciadas na PNA.

No que tange à Educação de Jovens e Adultos - EJA, as orientações presentes na PNA se contrapõem ao que vem sendo discutido nos Fóruns de EJA, que defendem uma abordagem metodológica fundamentada em princípios democráticos, participativos e dialógicos com vistas a uma alfabetização emancipadora e em articulação com a educação popular.

$\mathrm{Na}$ análise da PNA, a alfabetização de jovens, adultos e idosos é citada de forma superficial, e não assegura os paradigmas social, cultural e pedagógico da EJA, sem o diálogo com o pressuposto freiriano, que vem contribuindo para os avanços nas ações nesta área. Ao desconsiderar o pensamento de Paulo Freire e os paradigmas historicamente presentes nas políticas de EJA, há um evidente rompimento com os processos dialógicos e críticos que caracterizam a ação pedagógica nessa modalidade de ensino, fazendo com que o professor se limite a ser um mero transmissor da educação bancária, tão combatida pelo patrono da educação brasileira.

Por fim, salientamos que uma política de Alfabetização, seja na esfera nacional, estadual ou municipal, precisa ser resultado de um processo dialogado e construído 


\section{تilfoarẫ}

ISSN: 1984-6444 | http://dx.doi.org/10.5902/1984644455163

criando, no pós-pandemia, momentos e espaços para um amplo debate sobre a PMA, que permitissem à comunidade escolar analisar, discutir e propor uma política que atendesse às suas demandas, não dispensando consultas públicas para promover o diálogo com diferentes atores.

A definição de uma política com implicações tão importantes ficou restrita a um grupo de trabalho instituído pela Portaria $n^{\circ} 424 / 2020$, com "a finalidade de definir a política municipal de alfabetização", composto por um professor da Universidade de Cruzeiro do Sul do Estado de São Paulo e de mais 19 servidores da SEMED/Manaus, incluindo a secretária e subsecretária de educação. Nesse sentido é preciso que levantemos as seguintes questões: Onde estão as vozes dos professores? Onde aparece uma representatividade do corpo docente da SEMED no referido GT? Onde ficou o diálogo com as instituições públicas formadoras do Amazonas (IES), que em parceria com a SEMED já implementaram processos de formação continuada na área da alfabetização, à exemplo do PNAIC?

Observa-se que "nova" proposta ignora o percurso histórico da própria SEMED, construído nos últimos anos, bem como os fundamentos teórico-metodológicos amplamente discutidos e estudados nos seus programas de formação, inclusive expresso em seus documentos curriculares.

O conceito de alfabetização apresentado na Minuta é o mesmo conceito rudimentar apresentado na PNA do MEC, sobretudo, em relação à "instrução fônica sistematizada", pois caracteriza a opção pelo método fônico de forma exclusiva e assustadoramente reforçado (grifo nosso), no art.6, que estabelece as responsabilidades sobre a implementação da política municipal de alfabetização, inciso II, destacando especialmente as seguintes alíneas: 


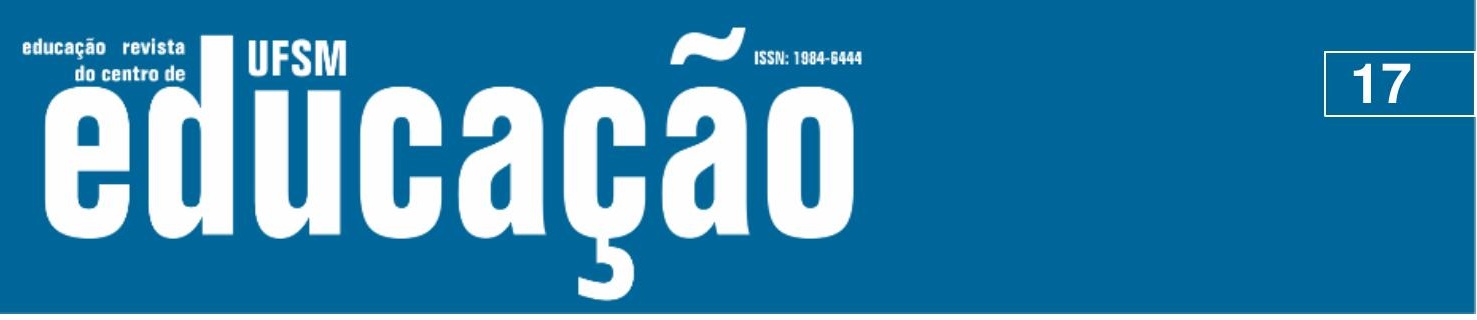

ISSN: 1984-6444 | http://dx.doi.org/10.5902/1984644455163

c) Desenvolver e/ou adquirir ou distribuir programas, materiais pedagógicos, orientação para o planejamento das aulas e recursos didáticos-pedagógicos de alfabetização, de literacia e de numeracia, fundamentados em evidências cientificas, a serem utilizados em toda rede;

m) Produzir guias de orientação e promover a compreensão de alfabetização baseada em evidências de acordo com a Ciência Cognitiva da Leitura (grifo nosso);

n) Desenvolver critérios e orientações para a sondagem das quatro fases do desenvolvimento da leitura e da escrita: fase pré-alfabética, fase alfabética parcial, fase alfabética completa e fase alfabética consolidada (grifo nosso).

É importante destacar que a SEMED/Manaus historicamente tem usado nas suas sondagens, os estágios de desenvolvimento da escrita, a partir do paradigma construtivista, fundamentado na teoria da psicogênese da escrita de Emília Ferreiro, paradigma esse presente em políticas passadas de formação de professores e que lamentavelmente são cobrados exaustivamente por meio de mapas pelos assessores pedagógicos, como instrumentos de controle.

A escolha pelo método fônico também se expressa na reportagem divulgada na página da SEMED, no dia 11/02/20 com o título Professor referência em linguística e alfabetização ministra oficina voltada para fortalecer ações do Ensino Fundamental $\mathrm{Na}$ reportagem em questão, é divulgada uma ação de formação do grupo de trabalho da Política Municipal de Alfabetização, realizada em tempo integral, nos dias 10 e 11 de fevereiro de 2020, que contou com a participação de gerentes pedagógicos e coordenadores das divisões distritais e setores pedagógicos da SEMED/Manaus, sem a participação dos professores, reduzidos a meros executores de uma política construída nos bastidores do poder.

A matéria apresenta uma fala da subsecretária da SEMED/Manaus, Euzenir Araújo, destacando que a importância do evento se deu pelo fato de contarem com a presença de um especialista na área da linguística e da alfabetização, informando que o palestrante da oficina, Renan Sargiani é ex-coordenador de neurociência cognitiva de linguística do MEC. Prossegue dizendo, que o professor é um especialista conceituado no Brasil, com experiência sobre a política nacional de alfabetização, vindo por meio do Banco Interamericano de Desenvolvimento para trabalhar na construção da política municipal de alfabetização, "para que a SEMED possa construir 


\section{OF HEM

ISSN: 1984-6444 | http://dx.doi.org/10.5902/1984644455163

ainda, almejamos que de fato este documento preliminar, ao se concretizar como uma política de estado para alfabetização, possa refletir os anseios da sociedade e represente um avanço para a educação, que $O$ debate da minuta em questão, nos convida também a refletir para além das concepções de alfabetização, requer um exercício de construção- desconstrução.

São inúmeras as armadilhas discursivas presentes no parecer técnico, demandando, portanto, um fortalecimento do movimento para que haja audiências públicas, com participação dos professores da Rede, representantes das universidades, associações científicas e outros representantes da sociedade civil brasileira.

Acreditamos que precisamos ser conduzidos pela emoção, pelo reconhecimento da nossa unicidade, pelo amor que nos humaniza e que nos alimenta de sonhos e de esperança para resistirmos a sucessivos golpes que ferem o estado democrático de direito, provocando a precarização do trabalho docente, determinado por uma divisão crescente do trabalho, derivado de um planejamento e controle externo cada vez maior.

Por fim, em conjunto com a representatividade de professores, foi constituída uma comissão do movimento PMA em Debate para estar presente nos novos encaminhamentos, visando um maior fortalecimento do movimento de resistência à minuta em questão, dentre eles: oficializar a comissão de professores com o apoio do SINTEAM para reivindicar a participação no GT da construção da Política Municipal de Alfabetização criado pela SEMED/Manaus; Promover lives para estudo e análise da minuta da PMA, visando o envolvimento de mais atores no processo de discussão; solicitar junto ao setor de estatística da SEMED com o apoio do sindicato, os resultados da pesquisa (questionário) sobre a minuta da PMA e o quantitativo de professores dos seguimentos da Educação Infantil e dos Anos Iniciais; solicitar e formalizar apoio institucional com as duas universidades públicas responsáveis pela formação inicial: FACED /UFAM e ENS/UEA; buscar apoio no Conselho Municipal de Educação e na Comissão de Educação da Câmara Municipal de Manaus, para a socialização das necessidades concretas dos professores e audiências públicas para a discussão da minuta. 


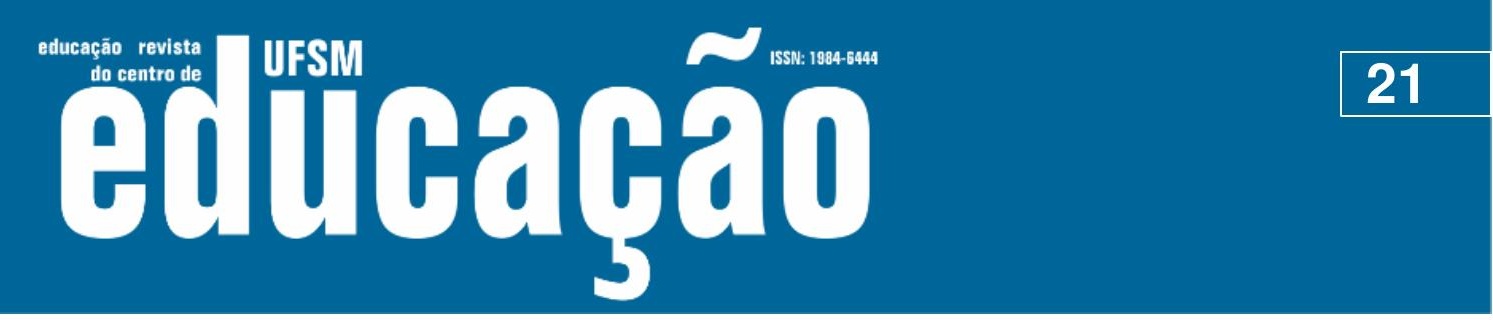

ISSN: 1984-6444 | http://dx.doi.org/10.5902/1984644455163

Diante do exposto, também deliberamos que os professores da comissão do PMA em Debate deverão buscar envolver seus pares, destacando que enquanto representantes de um grupo maior estarão reivindicando essas condições, bem como o que tem sido o grande empecilho nos oito anos de gestão dessa secretaria: a garantia do HTP dos professores e menos burocracia, resultada do excessivo controle da Gestão Integrada da Educação (GIDE), que descaracteriza o protagonismo e a autonomia da gestão pedagógica das equipes escolares.

As deliberações citadas coadunam com o pensamento de Cavalcante e Carneiro (2016, p. 61) ao discutirem sobre a práxis como dimensão norteadora do trabalho de formação docente e sobre a existência de uma tensão entre macro e micro. Para as autoras é preciso que lutemos por condições para um exercício de uma docência com decência, com direito de vivermos com dignidade, com tempo para ampliarmos as bases teóricas e epistemológicas, com tempo para o lazer, tendo a possibilidade de acesso ao patrimônio cultural necessário a uma formação unilateral, alertando que:

\begin{abstract}
Com cargas de trabalho massacrantes, com condições precárias de vida, o absolutamente necessário compromisso do educador se esvai ou vira retórica(...) urge, portanto, forjar uma nova consciência, propulsora de ações que revertam esse processo de globalização que existe em benefício de poucos, em favor de muitos, em favor da promoção humana, do processo de humanização. É necessário colocar a justiça como centro-fundamento de nossos esforços educativos. (...) compreender ter sempre em mãos as chaves da porta do afeto, da acolhida, do encontro com o outro. Este novo educador aposta na alegria, no sonho, na rigorosidade ética norteadora de novas relações no cotidiano, e não no discurso vazio de uma ética de conveniência (...) este novo educador se compromete. Enquanto se alia à luta pela construção de uma nova ordem social, mais justa, analisa os graves problemas macroeconômicos e suas repercussões na vida diária, assume o compromisso ético-político de, no cotidiano fazer valer sua opção pela humanização (CARNEIRO, 2016, p. 61)
\end{abstract}

É com essa sensibilidade que estamos tecendo esse novo tempo de cooperação coletiva entre os nossos pares, professores da Educação Básica, muitos deles recém-mergulhados em sua profissionalização, que precisam do apoio das universidades para continuar em seu processo de formação, e fazer da experiência política, um ato formativo. Um movimento que se nega a subtrair a autonomia docente, 


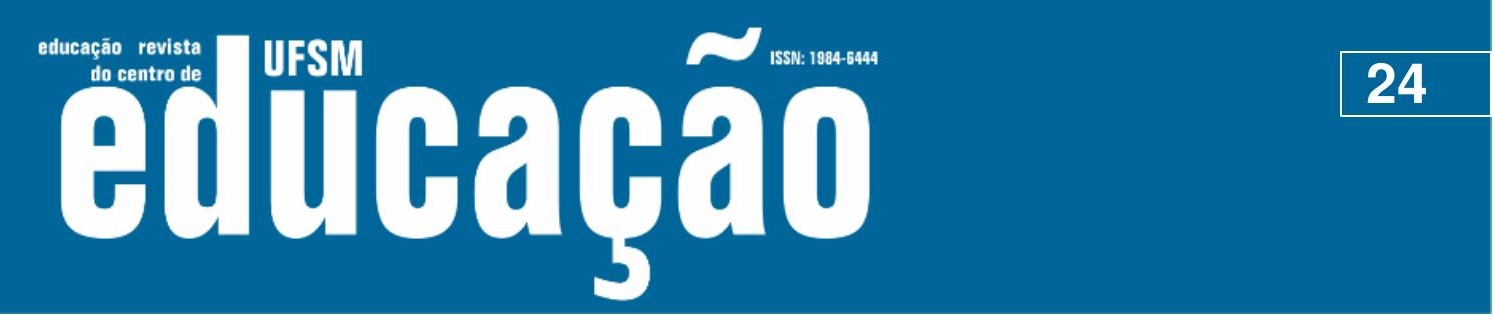

ISSN: 1984-6444 | http://dx.doi.org/10.5902/1984644455163

BRASIL, Ministério da Educação. Secretaria de educação Básica. Base Nacional Curricular Comum. 3av versão preliminar. Brasília: MEC, SEB, 2017.

BRASIL, Ministério da Educação. Secretaria de Alfabetização. PNA. Política Nacional de Alfabetização. Brasília: MEC, SEALF, 2019.

BRASIL, Ministério da Educação. Secretaria de Alfabetização. Conta para mim: guia de literacia familiar. Brasília: MEC, SEALF, 2019.

BUNZEN, Clecio. Um breve decálogo sobre o conceito de "literacia" na Política Nacional de Alfabetização (PNA,2019). In: Dossiê Política Nacional em foco: olhares de pesquisadores e professores. Revista Brasileira de Alfabetização/ Associação Brasileira de Alfabetização, Belo Horizonte: ABAlf vol.1, n.10, jul./dez.2019. p.44-51.

CAVALCANTI, Lucíola Inês Pessoa ; CARNEIRO, Cristina Rodrigues. A práxis na relação com a educação e a formação de professores: tensões e possibilidades de emancipação humana. In: CORRÊA, Carlos Humberto Alves; CAVALCANTI, Lucíola Inês Pessoa; BISSOLI, Michelle de Freitas.(Org.). Formação de professores em perspectiva. Manaus: EDUA.2016.

FRADE, Isabel Cristina Alves da Silva. A escrita na Política Nacional de Alfabetização. In: Dossiê Política Nacional em foco: olhares de pesquisadores e professores. Revista Brasileira de Alfabetização/ Associação Brasileira de Alfabetização, Belo Horizonte: ABAlf vol.1, n.10, jul./dez.2019. p.125-128.

MACIEL, Francisca Izabel Pereira. Onde estão as pesquisas sobre alfabetização no Brasil? In: Dossiê Política Nacional em foco: olhares de pesquisadores e professores. Revista Brasileira de Alfabetização/ Associação Brasileira de Alfabetização, Belo Horizonte: ABAlf vol.1, n.10, jul./dez.2019. p.58-59.

MADRUGADA CAMPONESA DE THIAGO DE MELLO. Disponível em: https://www.youtube.com/watch?v=rB30Vr8nW-I. Acesso em: 12 dez. 2019.

MANAUS. Proposta Pedagógica Anos Iniciais- Bloco Pedagógico. Secretaria Municipal de Educação. Departamento de Gestão Educacional. Divisão de Ensino Fundamental, 2014.

MANAUS. Secretaria Municipal de Educação. Plano Municipal de Educação de Manaus- PME /Manaus (2015- 2025). Prefeitura Municipal de Manaus.

MANAUS. Portaria nำ0424/2020-SEMED/GSA Secretária Municipal de Educação, no uso das atribuições que lhe são conferidas pelos incisos I e II do artigo 86, da Lei Orgânica do Município de Manaus. Diário Oficial do Município de Manaus. Manaus, AM, Ano XXI, Edição 4832, p.12, 5 maio 2020.

MELO NETO, João Cabral de. Tecendo a manhã. In: MELO NETO, João Cabral de. A educação pela pedra. Editora Alfaguara,1966, p.219. 


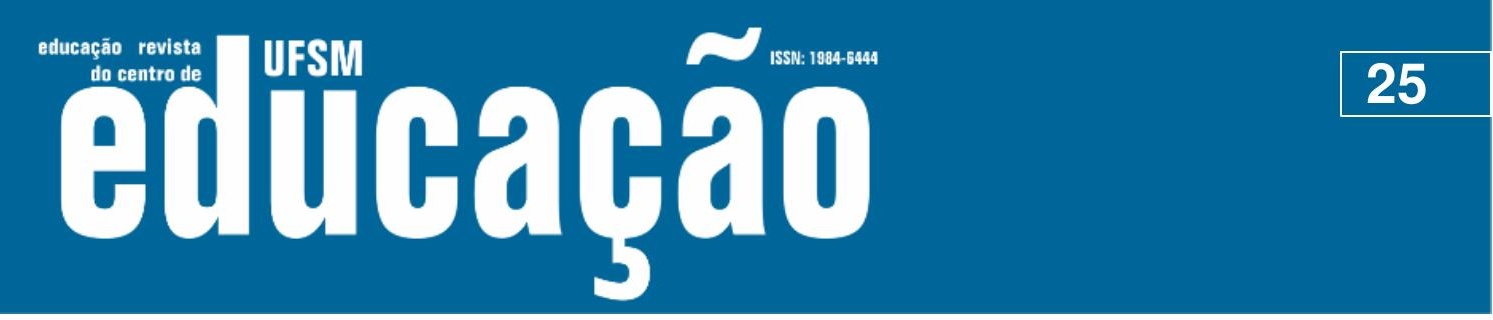

ISSN: 1984-6444 | http://dx.doi.org/10.5902/1984644455163

MICARELLO, Hilda. Alfabetização e evidências. In: Dossiê Política Nacional em foco: olhares de pesquisadores e professores. Revista Brasileira de Alfabetização/ Associação Brasileira de Alfabetização, Belo Horizonte: ABAlf vol.1, n.10, jul./dez.2019. p.60-62.

MORAIS, Artur Gomes. Análise crítica da PNA (Política Nacional de alfabetização) imposta pelo MEC através de decreto em 2019. .In: Dossiê Política Nacional em foco: olhares de pesquisadores e professores. Revista Brasileira de Alfabetização/ Associação Brasileira de Alfabetização, Belo Horizonte: ABAlf vol.1, n.10, jul./dez.2019. p.66-75.

MORTATTI, Maria do Rosário Longo. Alfabetização no Brasil: conjecturas sobre as relações entre políticas públicas e seus sujeitos privados. Revista Brasileira de Educação. vol.15, n.44, maio/ago., 2010.

MORTATTI, Maria do Rosário Longo. Brasil, 2091: notas sobre a "Política Nacional de Alfabetização". Revista OLHARES- Revista eletrônica do Departamento de Educação da Unifesp. v.7, n.3, nov. 2019b.

MORTATTI, Maria do Rosário Longo. A "política Nacional de Alfabetização" (Brasil, 2019): uma guinada (IDEO) metodológica para trás e pela direita. In: Dossiê Política Nacional em foco: olhares de pesquisadores e professores. Revista Brasileira de Alfabetização/ Associação Brasileira de Alfabetização, Belo Horizonte: ABAlf vol.1, n.10, jul./dez.2019. p.26-31.

PENNA, Fernando de Araújo. A defesa da "educação domiciliar" através do ataque à educação democrática: a especificidade da escola como espaço de dissenso. Linguagens, Educação e Sociedade, Teresina, ano 24, n.42, mai./ago.2019.

QUINTANA, Mário. Poeminho do contra. Disponível em: https://www.culturagenial.com/poeminho-do-contra-mario-quintana/. Acesso em: 05 maio 2020.

SOARES, Magda. Alfabetização: a questão dos métodos. São Paulo: Contexto, 2017.

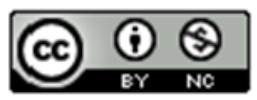

This work is licensed under a Creative Commons Attribution-NonCommercial 4.0 International (CC BY-NC 4.0)

\section{Notas}

\footnotetext{
1 Artigo produzido no GPPE/CNPq/UFAM junto à Linha 2 Estado, Políticas Públicas e Gestão da Educação do PPGEDA com apoio da CAPES e FAPEAM
} 
ISSN: 1984-6444 | http://dx.doi.org/10.5902/1984644455163

1 Fazendo alusão a canção Porto de Lenha de Zeca Torres "Torrinho". Fonte: https://www.youtube.com/watch?v=Oe05qFUY4-0. 